\title{
Industrial Effluents Harbor a Unique Diversity of Fungal Community Structures as Revealed by High-throughput Sequencing Analysis
}

\author{
Ramganesh Selvarajan ${ }^{1 *}$, Timothy Sibanda ${ }^{2}$, Sudharshan Sekar $^{3}$, Willem AJ Nel ${ }^{1}$ \\ ${ }^{1}$ Department of Agriculture and Environmental Sciences, UNISA Florida Campus, Florida, South Africa \\ ${ }^{2}$ Department of Biological Sciences, University of Namibia, Windhoek, Namibia \\ ${ }^{3}$ Center for Ecological Genomics and Wildlife Conservation, Department of Zoology, \\ University of Johannesburg, South Africa
}

Received:23 March 2018

Accepted: 6 May 2018

\begin{abstract}
The actual extent of fungal diversity in different environmental media is still a subject of ongoing research. Little is currently known about the diversity of fungal populations in industrial streams. This study characterized the fungal diversity of different industrial effluents using a high-throughput sequencing approach. A total of 234617 quality filtered reads were obtained from the collected wastewater samples. Phylogenetic taxonomy revealed that resident fungal communities were classified as 6 phyla, 31 classes, 79 orders, 144 families, and 192 genera. Ascomycota and Basidiomycota were the most dominant phyla whose relative abundance ranged from $23.29 \%$ to $38.31 \%$, and $17.34 \%$ to $33.51 \%$, respectively. Recovered operational taxonomic units (OTUs) ranged from 292 (Dixon) to 427 (Capegate). The existence of some fungal genera identified in the industrial wastewaters correlated to physicochemical variables and had the potential to play important roles in organic decomposition, pollutant degradation, and xenobiotic transformation. Meanwhile, the occurrence of unclassified fungal sequences $(22.5 \%$ to $33.09 \%)$ suggests that these effluents are a potential reservoir of as-yet uncharacterized fungal species.
\end{abstract}

Keywords: fungi, biodiversity, high-throughput sequencing, industrial wastewater, pollution

*e-mail: ramganesh.presidency@gmail.com, selvar@unisa.ac.za 


\section{Introduction}

Industrial effluents are characterized by a complex and variable composition of organic and inorganic pollutants including strong acids, metallic ions, and polyaromatic hydrocarbons (PAHs) [1, 2], representing a major source of surface and underground water pollution in many countries [3]. Also, these pollutants have the potential to exert selective pressure on microbial communities found therein. For instance, some studies suggest that the microbial abundance, as well as diversity in the aquatic environment, is influenced by various environmental parameters such as $\mathrm{pH}$, temperature, $\mathrm{DO}$, and salinity $[4,5]$. However, whichever geochemical parameter could be the primary determinant of microbial community composition, the presence or absence of particular nutrients or contaminants in the environment can potentially alter the microbial ecological niche, resulting in a direct impact on microbial community structure [6]. Some molecular tools like next-generation sequencing (NGS) analysis have provided practical opportunities to explore microbial ecology in different habitats, including thermal springs [7], microbial mats [8], saltpans [9], inland deserts [10], acid mine drainage [11], wastewater treatment plants $[12,13]$, and water reclamation plants [14]. To date, bacterial and archaeal communities from different industrial wastewaters have been widely surveyed $[13,15]$. However, this is not the case with fungal communities whose diversity has not been as extensively studied as bacteria and archaea.

Fungi are ubiquitous metabolically versatile heterotrophs with the ability to utilize various substrates ranging from lipids, proteins, complex carbohydrates, heteropolymers, aromatic hydrocarbons, and other recalcitrant anthropogenic chemicals as sole carbon sources [16]. They are involved in several pathways in wastewater treatment systems, including organic biodegradation [17], decolourization [18], and detoxification processes [19]. When compared to bacteria, fungi are more likely to be efficiently involved in bioremediation processes [20]. Their production of extracellular enzymes is of particular significance in their ability to degrade higher molecular weight pollutants such as polycyclic aromatic hydrocarbons (PAHs), organochlorine pesticides (OCPs), and polybrominated diphenyl ethers (PBDEs) [21]. Success in wastewater treatment requires stable indigenous microbial diversity and activity. To avoid runaway environmental pollution, mass production and the release of pollutant-laden wastewater mainly as a result of rapid growth of industrialization should be met by equally improved wastewater treatment systems. Identifying the fungal diversity in wastewater provides valuable insights regarding their adaptation and their potential involvement in bioremediation processes. Therefore, the aim of the study was to understand the indigenous fungal diversity found in different industrial effluents using high-throughput sequencing, as well as determining the impact of physicochemical factors on the fungal diversity of each individual sample using canonical correspondence analysis (CCA).

\section{Materials and Methods}

\section{Sample Collection}

Wastewater samples were collected from five industrial plants, among which was a plant responsible for the production of lead-acid automotive batteries (Dixon), high-tensile fencing and barbed wire (CWI), steel wire and its related products (Capegate), coating of steel in zinc (Ford), and washing of petrol and chemical tank trucks (Chemreem). Samples were collected in sterilized glass bottles and immediately stored in a cooler box $\left(4^{\circ} \mathrm{C}\right)$ for transportation to the laboratory at the University of South Africa (UNISA, Florida Campus, RSA). Physicochemical parameters such as temperature, $\mathrm{pH}$, conductivity, salinity, total dissolved solids (TDS), and dissolved oxygen (DO) were measured and recorded on site using a multi-parameter meter (Hanna Instruments PTY LTD, Johannesburg, RSA). Other analyses including chemical oxygen demand (COD), nitrate $\left(\mathrm{NO}_{3}\right)$, and phosphate $\left(\mathrm{PO}_{4}\right)$ were performed spectrophotometrically following the methodology of APHA [22] while the biochemical oxygen demand (BOD) was determined electrochemically.

\section{DNA Extraction and Sequencing}

Wastewater samples were homogenized and filtered through a $1.2 \mu \mathrm{m}$ pore-sized membrane filter to remove coarse particles. The filtrate was then passed through a $0.2 \mu \mathrm{m}$ pore-sized membrane filter to entrap the microbial cells onto the filter followed by cutting the membranes into pieces, which were then run on a Disruptor Genie (VWR, Pennsylvania, USA) to lyse the cells following the manufacturer's protocol. This was then followed by total DNA extraction using a Quick-gDNA MiniPrep Kit (ZYMO RESEARCH, Irvin, USA) according to the manufacturer's protocol. Following the DNA extraction, ITS1 (5'-CTTGGTCATTTAGAGGAAGTAA-3') and ITS4 (5' TCCTCCGCTTATTGATATGC-3') primers were used to amplify the ITS region as described [23] the internal transcribed spacer (ITS. PCR amplifications were conducted in $50 \mu \mathrm{L}$ volumes containing $25 \mu \mathrm{L}$ of one Taq 2X Master Mix, $1.5 \mu \mathrm{L}$ each of the forward and reverse primers at a concentration of $0.2 \mu \mathrm{M}$, $2 \mu \mathrm{L}$ of extracted DNA (50-100 ng $\left.\mu \mathrm{L}^{-1}\right)$, and $22 \mu \mathrm{L}$ of nuclease-free water. The thermal profile consisted of an initial denaturation step at $95^{\circ} \mathrm{C}$ for $2 \mathrm{~min}$, followed by 40 cycles of denaturation at $95^{\circ} \mathrm{C}$ for $30 \mathrm{~s}$, annealing at $55^{\circ} \mathrm{C}$ for $30 \mathrm{~s}$ and extension at $72^{\circ} \mathrm{C}$ for $1 \mathrm{~min}$, and a final extension phase performed at $72^{\circ} \mathrm{C}$ for $10 \mathrm{~min}$, followed by a holding phase at $4^{\circ} \mathrm{C}$. PCR amplicons were purified using a DNA Clean and Concentrator Kit (ZYMO RESEARCH, Irvin, USA). Following the purification step, the pooled PCR products were 
Supplementary Table 1. Physicochemical parameters of collected wastewater samples from five different industries.

\begin{tabular}{|c|c|c|c|c|c|c|}
\hline Parameters & Units & Capegate & Chemreem & CWI & Dixon & Ford \\
\hline Temperature & ${ }^{\circ} \mathrm{C}$ & $21.5 \pm 0.44$ & $19.39 \pm 0.01$ & $19.8 \pm 0.02$ & $20.4 \pm 0.48$ & $18.9 \pm 0.50$ \\
\hline $\mathrm{pH}$ & - & $11.5 \pm 0.07$ & $12.8 \pm 0.56$ & $10.4 \pm 0.04$ & $4.6 \pm 0.52$ & $8.5 \pm 0.01$ \\
\hline Dissolved oxygen & $\mathrm{mg} / \mathrm{L}$ & $1.85 \pm 0.01$ & $2.95 \pm 0.02$ & $2.06 \pm 0.01$ & $2.43 \pm 0.24$ & $1.26 \pm 0.12$ \\
\hline Conductivity & $\mu \mathrm{S} / \mathrm{cm}$ & $9224 \pm 33.6$ & $4979 \pm 43.5$ & $3555 \pm 21.02$ & $2703 \pm 13.9$ & $3921 \pm 24.2$ \\
\hline Salinity & Ppm & $5.17 \pm 0.07$ & $0.82 \pm 0.01$ & $22.81 \pm 0.37$ & $16.62 \pm 0.02$ & $2.05 \pm 0.01$ \\
\hline TDS & $\mathrm{mg} / \mathrm{L}$ & $4611 \pm 141.4$ & $2487 \pm 58.20$ & $1801 \pm 37.47$ & $1553 \pm 142.83$ & $1964 \pm 147.78$ \\
\hline Nitrate & $\mathrm{mg} / \mathrm{L}$ & $1.91 \pm 0.01$ & $3.93 \pm 0.05$ & $2.63 \pm 0.01$ & $8.77 \pm 0.02$ & $6.29 \pm 0.04$ \\
\hline Phosphate & $\mathrm{mg} / \mathrm{L}$ & $3.28 \pm 0.01$ & $7.76 \pm 0.14$ & $5.98 \pm 0.13$ & $9.25 \pm 0.88$ & $1.16 \pm 0.02$ \\
\hline Total Sulphur & $\mathrm{mg} / \mathrm{L}$ & $7.13 \pm 1.69$ & $15.7 \pm 3.46$ & $22.3 \pm 1.13$ & $450 \pm 84.14$ & $27.7 \pm 1.55$ \\
\hline Silicon & $\mathrm{mg} / \mathrm{L}$ & $3.66 \pm 0.03$ & $4.8 \pm 1.5$ & $0.2 \pm 0.01$ & $18.7 \pm 0.65$ & $3.65 \pm 0.2$ \\
\hline Calcium & $\mathrm{mg} / \mathrm{L}$ & $44.8 \pm 13.93$ & $324 \pm 34.64$ & $337 \pm 78.48$ & $19.2 \pm 0.98$ & $44.8 \pm 9.75$ \\
\hline Potassium & $\mathrm{mg} / \mathrm{L}$ & $12.1 \pm 1.06$ & $5.94 \pm 0.77$ & $53.3 \pm 8.48$ & $9.19 \pm 1.90$ & $6.44 \pm 0.60$ \\
\hline Magnesium & $\mathrm{mg} / \mathrm{L}$ & $14.5 \pm 0.49$ & $32.6 \pm 3.50$ & $94.6 \pm 6.35$ & $110 \pm 2.12$ & $4.55 \pm 0.44$ \\
\hline Sodium & $\mathrm{mg} / \mathrm{L}$ & $474 \pm 107.83$ & $299 \pm 34.5$ & $54.3 \pm 1.27$ & $264 \pm 26.16$ & $321.5 \pm 16.61$ \\
\hline Aluminium & $\mathrm{mg} / \mathrm{L}$ & $20.31 \pm 2.18$ & $19.4 \pm 3.29$ & $16.1 \pm 0.18$ & $16.2 \pm 2.43$ & $6.75 \pm 0.22$ \\
\hline Boron & $\mathrm{mg} / \mathrm{L}$ & $12.3 \pm 0.35$ & $22.5 \pm 0.60$ & $9.25 \pm 1.05$ & $0.2 \pm 0.01$ & $7.81 \pm 0.05$ \\
\hline Barium & $\mathrm{mg} / \mathrm{L}$ & Trace & $0.24 \pm 0.02$ & $0.2 \pm 0.01$ & Trace & Trace \\
\hline Lead & $\mathrm{mg} / \mathrm{L}$ & $0.2 \pm 0.01$ & $0.2 \pm 0.01$ & $0.43 \pm 0.02$ & $5.06 \pm 0.05$ & $0.2 \pm 0.01$ \\
\hline Strontium & $\mathrm{mg} / \mathrm{L}$ & $0.23 \pm 0.01$ & $0.61 \pm 1.13$ & $1.34 \pm 0.09$ & $6.61 \pm 0.99$ & $6.56 \pm 2.96$ \\
\hline Zinc & $\mathrm{mg} / \mathrm{L}$ & $0.78 \pm 0.02$ & $5.28 \pm 0.39$ & $8.51 \pm 2.28$ & $50.6 \pm 3.50$ & $207 \pm 17.21$ \\
\hline BOD & Ppm & $1.55 \pm 0.12$ & $1.39 \pm 0.09$ & $1.53 \pm 0.12$ & $1.83 \pm 0.67$ & $1.47 \pm 0.13$ \\
\hline COD & Ppm & $295.4 \pm 12.72$ & $948.6 \pm 93.16$ & $893.6 \pm 57.34$ & $534 \pm 72.83$ & $491.6 \pm 60.35$ \\
\hline
\end{tabular}

Measurable quantities of trace elements lower than $<0.2 \mathrm{mg} / \mathrm{L}$ considered as 'Trace'- chemical oxygen demand TDS-total dissolved solids, BOD - biological oxygen demand, COD - chemical oxygen demand; $\mathrm{n}=2$

*Unpublished data from Selvarajan et al. (2018)

sequenced on the Mi-Seq Illumina Sequencing Platform by Inqaba Biotechnology (Pretoria, South Africa).

\section{Post-sequence and Statistical Analysis}

The raw sequence data-set was initially cleaned of artificial replicates and low-quality reads using the nextgeneration sequencing Short Reads (ngsShoRT) trimmer as previously described [24]. Subsequently, all sequence reads were processed by the Mothur (v.1.39.5) pipeline following previous methods [25]. Paired-end reads were merged into contigs to avoid the generation of ambiguous bases in the overlap regions while reads with more than $1 \%$ of ambiguities or $8 \%$ of homopolymers were eliminated from further processing. The remnant contigs were then subjected to chimeric analysis using UCHIME according to the de novo method [26]. Non-chimeric reads were later aligned against the UNITEv6 database and a pairwise distance matrix was created from the curated aligned datasets to group sequences into operational taxonomic units (OTUs) at a confidence threshold of $95 \%$. Community richness indicators (Chaol) and diversity indices (Simpson-H) of the samples were calculated using PAST (University of Oslo, USA), while the heat map was generated using the omics tool of XLSTAT (Addinsoft, New York, USA). Canonical correspondence analysis (CCA) was used to visualize the pattern of industrial wastewater fungal community variation and distribution along with the measured environmental variables using PAST (University of Oslo, USA). All sequence reads were deposited into the GenBank (Sequence Reads Archive) under accession number SRP133043.

\section{Results and Discussion}

The physicochemical profiles of the different industrial wastewater samples are presented in Supplementary Table 1. In situ temperature of the 
Table 1. Summary of fungal diversity indices for collected industrial wastewater samples.

\begin{tabular}{|c|c|c|c|c|c|}
\hline Sample name & Raw reads & Processed reads & Total OTUs & Shannon $(\mathrm{H})$ & Chaol \\
\hline Capegate & 100145 & 53477 & 427 & 2.6 & 546.1 \\
\hline Chemreem & 42113 & 28853 & 375 & 2.79 & 600.1 \\
\hline CWI & 96137 & 74488 & 330 & 2.69 & 454.6 \\
\hline Dixon & 75315 & 50391 & 292 & 2.02 & 436.3 \\
\hline Ford & 40366 & 27408 & 370 & 3.09 & 616.8 \\
\hline
\end{tabular}

OTUs - Operational Taxonomic Units, Chao 1 - Community richness (higher number represents more richness),

Shannon - Community diversity (higher number represents more diversity)

wastewater during sample collection ranged from 18.9 to $21.5^{\circ} \mathrm{C}$. Dixon wastewater had highly acidic $\mathrm{pH}(4.6)$ while the others had slight to highly alkaline $\mathrm{pH}$ ranging from 8.5 (Ford) to 12.8 (Chemreem), possibly as a result of the presence of large amounts of alkaline-based chemicals used in the industries. With the exception of Dixon, the $\mathrm{pH}$ values of other industrial wastewaters were within the prescribed limits as determined by the South African Department of Water Affairs [27]. The concentration of total dissolved solids (TDS) was high in Capegate $(4611 \mathrm{mg} / \mathrm{L})$ compared to other industrial effluents whose TDS readings ranged from 1553 to $2487 \mathrm{mg} / \mathrm{L}$. The amount of dissolved oxygen (DO) was low in all samples, ranging from $1.26 \mathrm{mg} / \mathrm{L}$ in Ford to $2.95 \mathrm{mg} / \mathrm{L}$ in Chemreem. Among the nutrients, the concentration of sulphur was significantly higher $(p<0.05)$ in Dixon wastewater $(450 \mathrm{mg} / \mathrm{L})$ compared to wastewater from other sites, where it ranged 7.13-27.7 mg/L. Similarly, the concentration of phosphate (1.16-9.25 ppm) was relatively higher than nitrate (1.91-8.77 ppm) in four industrial effluents except the Ford sample. Phosphate values exceeding $0.1 \mathrm{ppm}$ are associated with eutrophication and natural water degradation [28]. The levels of COD exceeded $400 \mathrm{mg} / \mathrm{L}$ in four industries except Capegate (S. Table 1), which is over the limit values set by the Department of Water Affairs [27] for discharge of wastewater into a water resource or irrigation of any land.

Exploration of fungal biodiversity in aquatic habitats is gaining momentum as new molecular tools and approaches like next-generation sequencing have revealed an unexpected abundance of fungi with unidentified ecological functions and unclear phylogenetic placement [29]. A total of 234617 quality filtered reads were obtained from the collected wastewater samples after removal of PCR artifacts and chimeric sequences, and used for further analysis. The complete phylogenetic taxonomy analysis assigned the fungal reads to 6 phyla, 31 classes, 79 orders, 144 families, and 192 genera in all industrial wastewater samples. Chao-1 index, considered a species richness estimator, showed the lowest number of species in Dixon wastewater (436.3) and the highest in Ford effluent (616.8). The observed low species richness of the fungal communities was in agreement with observations of a previous study that reported low fungal species richness in mine wastewater [11]. Similar to the Chao-1 index, species diversity as estimated by the Shannon-H index was highest in Ford wastewater (3.09) and lowest in Dixon wastewater (2.02). This observation supports the findings of Ferreira et al. [30], who reported lower fungal diversity and species richness in highly contaminated environments. Detailed information concerning the recovered OTUs, observed sequences, Chao-1, and Shannon indices are shown in Table 1.

Phylogenetic diversity of fungi in the environment is still largely overlooked [16], especially where industrial wastewater is concerned. The phylum-level phylogenetic fingerprint of fungal communities in this study produced a total of 6 phyla dominated by Ascomycota whose relative abundance ranged from $23.29 \%$ in Dixon to $38.31 \%$ in Ford samples, followed by Basidiomycota with a relative abundance of $17.34 \%$ in Capegate to $33.51 \%$ in Chemreem effluents. Similar to the present findings, previous studies on fungal diversity in industrial wastewater treatment plants using clone libraries found fungal communities to be dominated by fungi of the phyla Ascomycota and Basidiomycota $[16,20,31]$. The overwhelming abundance of fungi belonging to these two phyla may be attributed to the fact that Ascomycota constitutes the largest phylum of fungi encompassing more than 33,000 named species

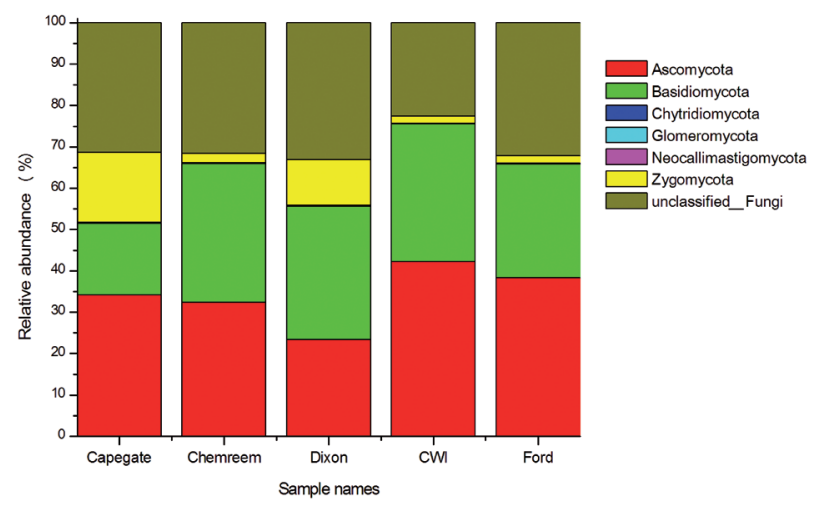

Fig. 1. Relative abundance of fungal phyla from five different industrial effluents; sequences that could not be classified into any known group were designated "Unclassified" fungi 
Supplementary Table 2. Relative abundances of fungal classes from five different industrial effluents.

\begin{tabular}{|c|c|c|c|c|c|c|}
\hline Phylum & Class & Capegate & Chemreem & CWI & Dixon & Ford \\
\hline \multirow{13}{*}{ Ascomycota } & Arthoniomycetes & 0.029933 & 0.020827 & 0.005369 & 0.001985 & 0.018245 \\
\hline & Ascomycota_Incertae sedis & 0.001871 & 0.010413 & 0.001342 & 0 & 0.010947 \\
\hline & Dothideomycetes & 4.888407 & 8.459162 & 21.95852 & 0.180602 & 20.47072 \\
\hline & Eurotiomycetes & 41.37841 & 10.59391 & 6.805826 & 1.057813 & 15.17606 \\
\hline & Lecanoromycetes & 1.094419 & 3.394772 & 5.733271 & 0.075416 & 0.357599 \\
\hline & Leotiomycetes & 0.114119 & 0.211739 & 0 & 0.02977 & 0.076628 \\
\hline & Neolectomycetes & 0.003742 & 0.010413 & 0 & 0 & 0.007298 \\
\hline & Orbiliomycetes & 0.044899 & 0.104134 & 0.014766 & 0.001985 & 0.072979 \\
\hline & Pezizomycetes & 0.907339 & 1.565483 & 1.057789 & 0.281819 & 0.817369 \\
\hline & Pezizomycotina_Incertae sedis & 0.067349 & 0.03124 & 0.024163 & 0.065493 & 0.051086 \\
\hline & Saccharomycetes & 13.3463 & 20.6012 & 18.5046 & 32.76242 & 14.72724 \\
\hline & Sordariomycetes & 2.048529 & 2.297893 & 0.438956 & 0.35922 & 4.63784 \\
\hline & Taphrinomycetes & 0.001871 & 0 & 0.001342 & 0.001985 & 0 \\
\hline \multirow{11}{*}{ Basidiomycota } & Agaricomycetes & 27.86373 & 38.02284 & 28.54286 & 45.10687 & 34.52655 \\
\hline & Agaricomycotina_Incertae sedis & 0 & 0 & 0 & 0.001985 & 0 \\
\hline & Agaricostilbomycetes & 0.09354 & 0.128432 & 0.151688 & 0.083355 & 0.065681 \\
\hline & Basidiomycota_Incertae sedis & 0.009354 & 0.003471 & 0 & 0 & 0.007298 \\
\hline & Cystobasidiomycetes & 0.969076 & 2.280537 & 4.189543 & 0.067478 & 1.193213 \\
\hline & Exobasidiomycetes & 0.132827 & 0.055538 & 0.911471 & 0.468375 & 0.280971 \\
\hline & Microbotryomycetes & 0.467701 & 0.617862 & 0.371837 & 0.623177 & 0.368546 \\
\hline & Pucciniomycetes & 0.166501 & 0.18397 & 0.067119 & 0.319527 & 0.156906 \\
\hline & Tremellomycetes & 1.565862 & 4.79017 & 1.716894 & 0.200449 & 1.386608 \\
\hline & Ustilaginomycetes & 0.527566 & 2.811621 & 2.365259 & 1.436879 & 0.737092 \\
\hline & Ustilaginomycotina_Incertae sedis & 0.684714 & 0.079836 & 4.686221 & 0.08137 & 1.857325 \\
\hline Chytridiomycota & Chytridiomycetes & 0.28062 & 0.208268 & 0.033559 & 0.321512 & 0.207991 \\
\hline Glomeromycota & Glomeromycetes & 0.095411 & 0.159672 & 0.033559 & 0.017862 & 0.113118 \\
\hline Neocallimastigomycota & Neocallimastigomycetes & 0.054253 & 0.079836 & 0.010739 & 0.021831 & 0.047437 \\
\hline \multirow{4}{*}{ Zygomycota } & Kickxellomycotina_Incertae sedis & 0.456476 & 0.479017 & 1.355796 & 0.444559 & 0.302864 \\
\hline & Mucoromycotina_Incertae sedis & 2.246834 & 2.44021 & 0.963823 & 15.94856 & 1.963145 \\
\hline & Zoopagomycotina_Incertae sedis & 0.458347 & 0.354056 & 0.053695 & 0.035724 & 0.361248 \\
\hline & Entomophthoromycotina_Incertae sedis & 0 & 0.003471 & 0 & 0.001985 & 0 \\
\hline
\end{tabular}

and a vast number of undescribed fungi [32], while Basidiomycetes houses fungi that are known for their exceptional adjustment abilities to adapt to detrimental environmental conditions [33].

Phylum Zygomycota was the third most dominant phyla whose relative abundance ranged from $16.90 \%$ (Capegate) to $1.78 \%$ (Ford), whereas the other phyla including Chytridiomycota, Glomeromycota, and Neocallimastigomycota occurred in low percentages $(<1 \%)$. The occurrence of the fungal phyla
Glomeromycota and Neocallimastigomycota in industrial wastewater corroborates the findings of Maza-Márquez et al. [16], who reported the occurrence of the same in urban wastewater treatment plants in Spain. Unclassified fungal sequences occurred at relatively high abundance ranging from $22.50 \%$ in CWI to $33.09 \%$ in Dixon effluent samples, hypothetically suggesting that these samples may contain novel fungal species. The detailed distribution of the fungal phyla across different industrial wastewater is given in Fig. 1. 
Ascomycota are the prime fungal group, accounting for more than $65 \%$ of fungal community compositions in both terrestrial and aquatic environments and playing a key role in the decomposition of organic matter and transformation of pollutants [16]. In our study, the dominant fungal classes within the phylum Ascomycota included Eurotiomycetes, Saccharomycetes, Dothideomycetes, Lecanoromycetes, and Pezizomycetes (S. Table 2). The most dominant genera identified within the class Eurotiomycetes was Exophiala spp., whose relative abundance ranged from $40.55 \%$ in Capegate to $0.74 \%$ in CWI (Fig. 2). Exophiala is a dimorphic fungus capable of degrading several volatile organic compounds (VOCs), including ethylbenzene [34], and have been found to thrive in conditions contaminated with these particular compounds. Our samples were collected from the industries where they release large quantities of volatile organic compounds (VOCs) [35]; and the high abundance of fungi of the genus Exophiala in these samples corroborates earlier findings. Candida was the second most dominant genera belonging to the class Saccharomycetes, with a relative abundance of between $26.92 \%$ in CWI to $11.72 \%$ in Capegate. Previous studies suggested that Candida spp. were the most frequently cultured fungi recovered from anoxic-activated sludge samples [36] and industrial wastewater [37]. Members of the genus Candida have the ability to adsorb and/or accumulate metals from their surroundings, also in addition to their ability to produce extracellular polymeric substances for biofilm formation, flocculation, and adhesion processes [20]. Perhaps their most important contribution as it relates to wastewater treatment is that they limit bacterial contamination and so improve the secondary industrial wastewater treatment process [38]. After Candida spp., the third most dominant genera identified across all samples was Davidiella, whose abundance ranged from $11.33 \%$ in CWI to $0.02 \%$ in the Dixon sample. Oh et al. [39] previously characterized fungal communities in air samples collected in Korea and reported that 50\% of their identified metagenomic sequences belonged to the genus Davidiella. The identification of Davidiella in wastewater samples, as in the present study, suggests that though fungi of this genera are mostly airborne, their spores can land typically on any environmental media and be able to proliferate. Health-wise, this fungus is an allergy-inducing pathogen found to be abundant in urban and industrial areas [39]. Some rare fungal genera like Imaia, Teratosphaeria, and Karoowia were also identified in industrial wastewater samples in this study (Fig. 2), although information regarding their metabolic abilities and other functional activities remains largely unavailable to date.

Dominant sequences from the phylum Basidiomycota were distributed to the classes such Agaricomycetes and Tremellomycetes at $27.86-45.11 \%$ and $0.22-4.79 \%$,

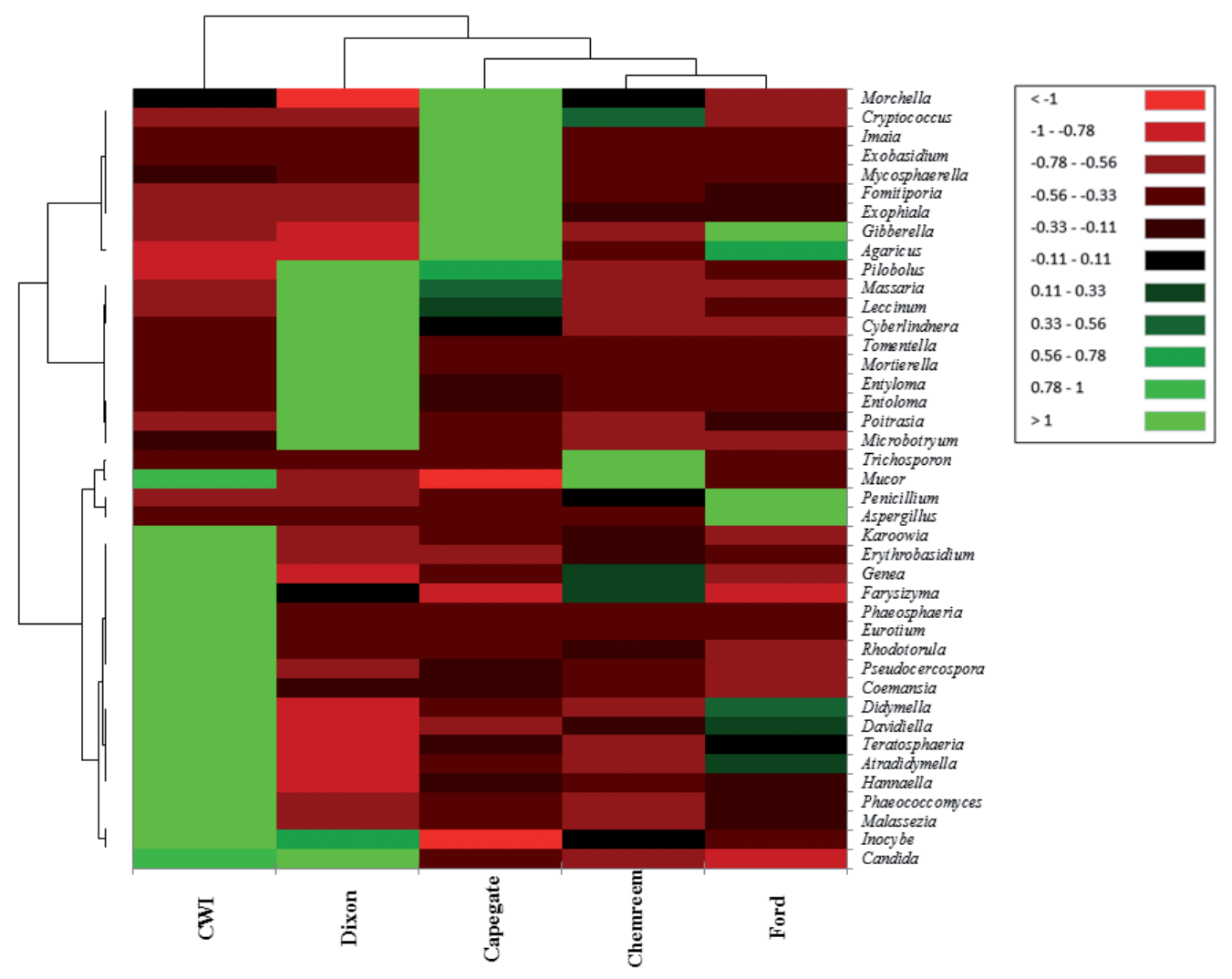

Fig. 2. Heat map graph of hierarchy cluster for the top 10 genera; the color intensity indicates the relative abundance of each genus within each sample 


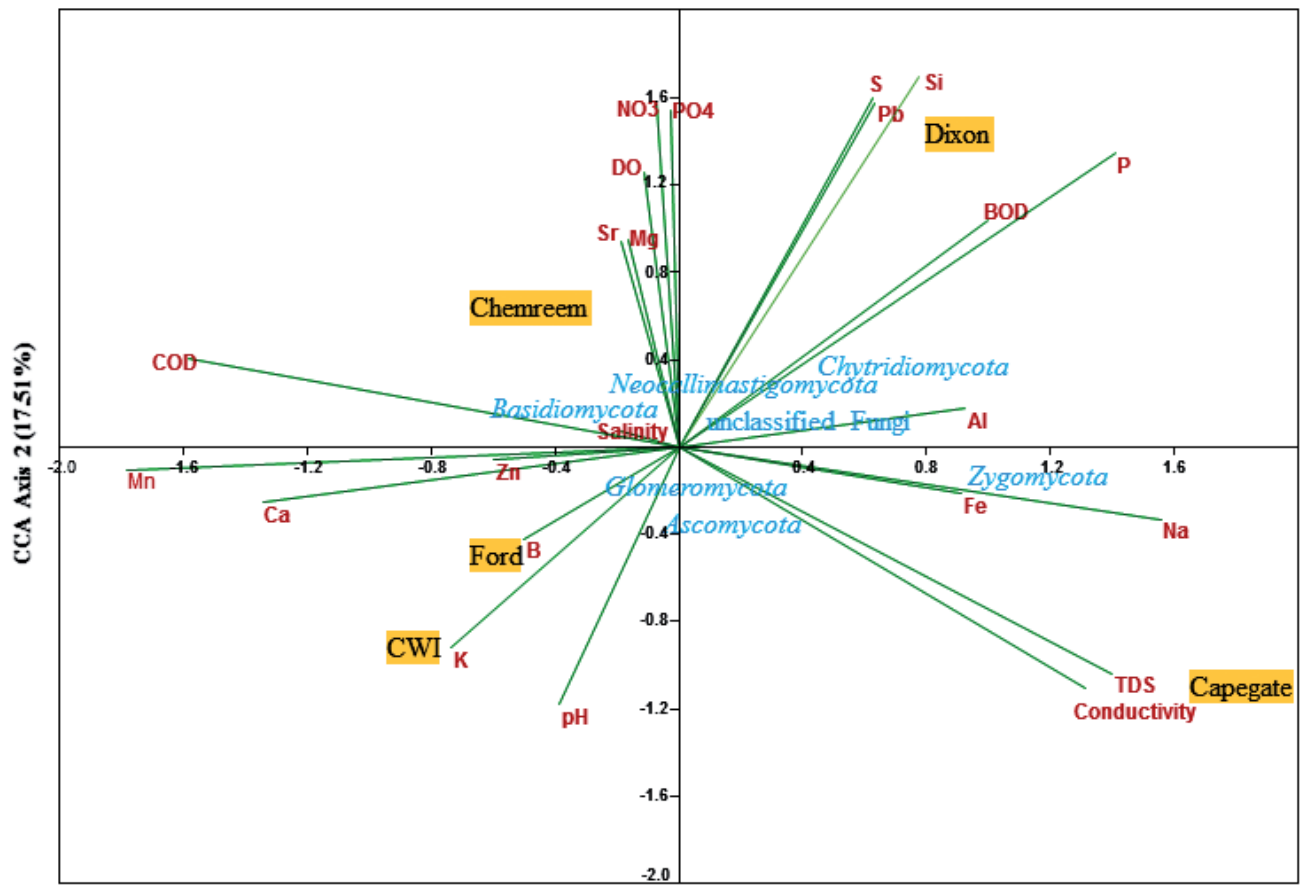

CCA Axis 1(81.98\%)

Fig. 3. Canonical correspondence analysis (CCA) showing the distribution and interrelationships of the fungal phyla and physicochemical parameters in industrial wastewater.

respectively (S. Table 2). OTUs belonging to the genera Inocybe were dominant in all industrial samples except Capegate (Fig. 2). According to a recent study by Bahram et al. [40], the genus Inocybe belongs to the class Agaricomycetes, an ectomycorrhizal fungi known for possessing a repertoire of genes encoding cellulosedegrading enzymes to break complex cellulose to simple organic compounds that become readily available for bacteria, a function that supports symbiosis between fungi and bacteria. Moreover, the OTUs belonging to the class Agaricomycetes - such as Agaricus (Capegate), Fomitoporia (Chemreem, CWI and Ford), and Entoloma (Dixon) - were the most prominent genera of any phyla found in this study. Judging from the findings of Buée et al. [41], who analyzed the fungal diversity from different soil samples using pyrosequencing and reported observing that $73 \%$ of their identified OTUs belonged to the class Agaricomycetes, it confirms that this fungal phylum is found in different environmental media milieu. Also, these members are common to soil and aquatic environments with a strong representation of the ectomycorrhizal species, and play important functions in ecosystems facing various environmental stresses [41].

Besides the dominant genera, other common genera with low sequence abundance in analyzed wastewater samples include Aspergillus (Capegate - 1.66\%), Penicillium (Ford - 1.59\%), Trichosporon (Chemreem $3.10 \%$ ), Mortierella (Dixon - 9.66\%), and Rhodotorula (CWI $-1.18 \%$ ). Contrary to our findings, Viegas et al. [42] reported that fungal genera such as Penicillium and
Aspergillus were the most frequently encountered genera in domestic wastewater. Aspergillus have a high capacity to reduce the phenolic compounds with significant reduction of COD in industrial wastewater [43]. Fungi of the genus Penicillium are known to improve the bioconversion of organic compounds and enhance the dewaterability and filtration during wastewater treatment [20]. Previously, Trichosporon spp. isolated from petroleum polluted sediment has been reported to be highly involved in biofilm formation and degradation of aromatic compounds [44]. Additionally, fungi of the genus Trichosporon serve as promising candidates for decaffeination processes in food industries [45]. Fungi of the genus Rhodotorula are frequently found in polluted environments and are able to catabolize a range of organic contaminants such as pyrene, anthracene phenanthrene, and benzopyrene [46]. The genus Mortierella (Dixon) is the only dominant genus belonging to the phylum Zygomycota that was identified in this study. Species from this genus are commonly found in soil ecosystems and have the ability to degrade a variety of herbicides such as isoproturon and diuron [47]. The present findings therefore hypothetically suggest that the fungi existing in industrial effluents might contribute greatly to pollutant degradation, symbiotic interaction, and biofilm formation during wastewater treatment processes.

This study further investigated the relationship between the abiotic factors and fungal diversity of each industrial stream using canonical correspondence analysis (CCA) (Fig. 3). CCA Axis 1 explained 77.94\% 
of the variance while Axis 2 explained $16.62 \%$ of the variance in the fungal-environmental parameters relationship. Also, it explained that the phyla Ascomycota / Zygomycota displayed a strong converse relationship with Chytridiomycota/Glomeromycota and Neocallimastigomycota - a finding that is in agreement with knowledge of phylum relationships in wastewater systems [16]. Members of Basidiomycota and Glomeromycota were positively correlated with $\mathrm{NO}_{3}$ and $\mathrm{PO}_{4}$ concentrations. Trichosporon (Basidiomycota) have been reported to be able to denitrify and could cooperate with bacteria in nitrogen removal [20], while Archaeosporales (Glomeromycota) enhance phosphorous and nitrogen supply to host [48]. Fungi of the phylum Ascomycota were observed to be negatively influenced by $\mathrm{pH}$, which agrees with the findings of Maza-Marquez et al. [16], who reported similar findings in wastewater treatment systems. Metals such as $\mathrm{Mg}, \mathrm{Sr}, \mathrm{Si}$, and $\mathrm{Pb}$ have positively influenced the occurrence of Basidiomycota, Chytridiomycota, and Neocallimastigomycota, while B, Fe, and $\mathrm{Zn}$ were correlated with the presence of Ascomycota and Zygomycota, respectively. A previous study [48] reported that metals such as $\mathrm{Ni}, \mathrm{Co}, \mathrm{Mo}, \mathrm{V}, \mathrm{Fe}, \mathrm{Mg}$, and $\mathrm{Mn}$ were the most important parameters influencing microbial composition in the environment.

\section{Conclusions}

The results of the present study provide the diversity and abundance of fungal communities from different industrial effluents using high throughput sequence analysis. The complete phylogenetic taxonomy analysis showed that the fungal reads were distributed to 6 phyla, 31 classes, 79 orders, 144 families, and 192 genera in all industrial wastewater samples. The core genera were found to be highly influenced by physicochemical parameters and have previously been linked to organic decomposition, pollutant degradation, and xenobiotic transformation. The occurrence of unclassified fungal sequences $(22.5 \%$ to $33.09 \%$ ) suggests that these effluents are a potential reservoir of diverse fungal communities that are yet to be characterized. Further research is encouraged in future to identify the functional properties and interaction mechanisms between fungal and bacterial species with the potential for application in bioremediation initiatives.

\section{Acknowledgements}

The authors are thankful to the University of South Africa (UNISA) for supporting this research. We are also grateful to the industrial owners for allowing researchers to sample their effluent tanks. Sincere thanks to Mrs. Eunice Iloms for obtaining permissions and collecting samples.
Further, the authors would also like to thank the Centre for High Performance Computing (CHPC) facility, South Africa for providing computational support for sequence data analysis.

\section{Conflict of Interest}

The authors declare that they have no conflict of interests to this work.

\section{References}

1. ORISAKWE O.E., ASOMUGHA R., AFONNE O.J., ANISI C.N., OBI E., DIOKA C.E. Impact of effluents from a car battery manufacturing plant in Nigeria on water, soil, and food qualities. Arch. Environ. Health. 59 (1), 31, 2004.

2. TEKERE M., SIBANDA T., MAPHANGWA K.W. An assessment of the physicochemical properties and toxicity potential of carwash effluents from professional carwash outlets in Gauteng Province, South Africa. Environ. Sci. Pollut. Res. 23 (12), 11876, 2016.

3. BASSIN J.P., RACHID C.T. C.C., VILELA C., CAO S. M.S., PEIXOTO R.S., DEZOTTI M. Revealing the bacterial profile of an anoxic-aerobic moving-bed biofilm reactor system treating a chemical industry wastewater. Int. Biodeterior. Biodegrad. 120, 152, 2017.

4. RANJARD L., LEJON D.P.H., MOUGEL C., SCHEHRER L., MERDINOGLU D., CHAUSSOD R. Sampling strategy in molecular microbial ecology: Influence of soil sample size on DNA fingerprinting analysis of fungal and bacterial communities. Environ. Microbio. 5 (11), 1111, 2003.

5. SOMBOONNA N., ASSAWAMAKIN A., WILANTHO A., TANGPHATSORNRUANG S., TONGSIMA S. Metagenomic profiles of free-living archaea, bacteria and small eukaryotes in coastal areas of Sichang island, Thailand. BMC genomics. 13 (7), S29, 2012.

6. LEE Z. M.P., PORET-PETERSON A.T., SIEFERT J.L., KAUL D., MOUSTAFA A., ALLEN A.E., ELSER J.J. Nutrient stoichiometry Shapes Microbial Community Structure in an Evaporitic Shallow Pond. Front. Microbiol. 8 (6), 1, 2017.

7. MAGNABOSCO C., TEKERE M., LAU M. C.Y., LINAGE B., KULOYO O., ERASMUS M., ONSTOTT T. C. Comparisons of the composition and biogeographic distribution of the bacterial communities occupying South African thermal springs with those inhabiting deep subsurface fracture water. Front. Microbiol. 5 (679), 1, 2014.

8. RAMGANESH S., TIMOTHY S., MEMORY T. Thermophilic bacterial communities inhabiting the microbial mats of "indifferent" and chalybeate (iron-rich) thermal springs: diversity and biotechnological analysis. Microbiol. open. Accepted In press. 2017.

9. SELVARAJAN R., SIBANDA T., TEKERE M., NYONI H., MEDDOWS-TAYLOR S. Diversity Analysis and Bioresource Characterization of Halophilic Bacteria Isolated from a South African Saltpan. Molecules. 22 (4), 657, 2017.

10. ABED R. M.M., KLEMPOVA T., GAJDOS P., CERTIK M. Bacterial diversity and fatty acid composition of hypersaline cyanobacterial mats from an inland desert wadi. J. Arid Environ. 115, 81, 2015. 
11. KAMIKA I., AZIZI S., TEKERE M. Microbial profiling of South African acid mine water samples using next generation sequencing platform. Appl. Microbiol. Biotechnol.100, 6069, 2016.

12. SHCHEGOLKOVA N.M., KRASNOV G.S., BELOVA A.A., DMITRIEV A.A., KHARITONOV S. L., KLIMINA K. M., KUDRYAVTSEVA A. V. Microbial community structure of activated sludge in treatment plants with different wastewater compositions. Front. Microbiol. 7 (2), $1,2016$.

13. MEERBERGEN, K., VAN GEEL, M., WAUD, M., WILLEMS, K.A., DEWIL, R., VAN IMPE, J., LIEVENS, B. Assessing the composition of microbial communities in textile wastewater treatment plants in comparison with municipal wastewater treatment plants. Microbiol. open. 6 (1), 1, 2017.

14. SEKAR S., ZINTCHEM A.A.E.A., KESHRI J., KAMIKA I., MOMBA M.N.B. Bacterial profiling in brine samples of the Emalahleni water reclamation plant, South Africa, using 454-pyrosequencing method. FEMS Microbiol. Lett. 359 (1), 55, 2014.

15. MA Q., QU Y., SHEN W., ZHANG Z., WANG J., LIU Z., ZHOU, J. Bacterial community compositions of coking wastewater treatment plants in steel industry revealed by Illumina high-throughput sequencing. Bioresour. Technol. 179, 436, 2015.

16. MAZA-MÁRQUEZ P., VILCHEZ-VARGAS R., KERCKHOF F.M., ARANDA E., GONZÁLEZ-LÓPEZ J., RODELAS B. Community structure, population dynamics and diversity of fungi in a full-scale membrane bioreactor (MBR) for urban wastewater treatment. Water Res. 105, 507, 2016.

17. SANNINO F., NUZZO A., VENTORINO V., PEPE O., PICCOLO, A. Effective degradation of organic pollutants in aqueous media by microbial strains isolated from soil of a contaminated industrial site. Chem. Biol. Technol. Agric. 3 (1), 2, 2016.

18. SENTHILKUMAR S., PERUMALSAMY M., JANARDHANA PRABHU H. Decolourization potential of white-rot fungus Phanerochaete chrysosporium on synthetic dye bath effluent containing Amido black 10B. J. Saudi Chem. Soc. 18 (6), 845, 2014.

19. LAPP K., VODISCH M., KROLL K., STRASSBURGER M., KNIEMEYER O., HEINEKAMP T., BRAKHAGE A.A. Characterization of the Aspergillus fumigatus detoxification systems for reactive nitrogen intermediates and their impact on virulence. Front. Microbiol. 5 (9), 1, 2014.

20. NIU L., LI Y., XU L., WANG P., ZHANG W., WANG C., WANG L. Ignored fungal community in activated sludge wastewater treatment plants: diversity and altitudinal characteristics. Environ. Sci. Pollut. Res. 24 (4), 4185, 2017.

21. GHOSAL D., GHOSH S., DUTTA T.K., AHN Y. Current state of knowledge in microbial degradation of polycyclic aromatic hydrocarbons (PAHs): A review. Front. Microbiol. 7 (8), 1369, 2016.

22. APHA. Standard Methods for the Examination of Water and Wastewater, 20 $0^{\text {th }}$ ed.; American Public Health Association: Washington, DC, 2001.

23. OP DE BEECK M., LIEVENS B., BUSSCHAERT P., DECLERCK S., VANGRONSVELD J., COLPAERT, J.V. Comparison and validation of some ITS primer pairs useful for fungal metabarcoding studies. PLoS One. 9 (6), e97629, 2014.
24. CHEN C., KHALEEL S.S., HUANG H., WU C.H. Software for pre-processing Illumina next-generation sequencing short read sequences. Source Code Biol. Med. 9 (8), 1, 2014.

25. SCHLOSS P.D., WESTCOTT S.L., RYABIN T., HALL J.R., HARTMANN M., HOLLISTER E.B., LESNIEWSKI R.A., OAKLEY B.B., PARKS D.H., ROBINSON C.J., SAHL J.W., STRES B., THALLINGER G.G., VAN HORN D.J., WEBER C.F. Introducing mothur: OpenSource, Platform-Independent, Community-Supported Software for Describing and Comparing Microbial Communities. Appl. Environ. Microbiol. 75 (23), 7537, 2009.

26. EDGAR R.C., HAAS B.J., CLEMENTE J.C., QUINCE C., KNIGHT R. UCHIME improves sensitivity and speed of chimera detection. Bioinformatics 27 (16), 2194, 2011.

27. DWA. Revision of General Authorisations in Terms of Section 39 of the National Water Act, 1998 (Act No. 36 of 1998) (the Act). Gazette. 19182, 42, 2013.

28. SHRESTHA A. M., NEUPANE S., BISHT, G. An Assessment of Physicochemical Parameters of Selected Industrial Effluents in Nepal. J. Chem. 2017, 1, 2017.

29. GROSSART H.P., WURZBACHER C., JAMES T.Y., KAGAMI, M. Discovery of dark matter fungi in aquatic ecosystems demands a reappraisal of the phylogeny and ecology of zoosporic fungi. Fungal Ecol. 19, 28, 2016.

30. FERREIRA V., GONÇALVES A.L., PRATAS J., CANHOTO C. Contamination by uranium mine drainages affects fungal growth and interactions between fungal species and strains. Mycologia 102 (5), 1004, 2010.

31. TAHIR A. Resistant Fungal Biodiversity of Electroplating Effluent and Their Metal Tolerance Index. In Electroplating. Lahore: InTech, 137, 2012.

32. MONEY N.P. Fungal diversity. In S.C. Watkinson, L. Boddy, N.P. Money (Eds.), The Fungi (Third Edii.,). Academic press. 1, 2016.

33. PERALTA R.M., SILVA B.P., CORRÊA R.C.G., KATO C.G., SEIXAS F.A.V., BRACHT A. Enzymes from basidiomycetes: peculiar and efficient tools for biotechnology. In G. Brahmachari, A.L. Demain J.L. Adrio (Eds.), Biotechnology of Microbial Enzymes: Production, Biocatalysis and Industrial Applications. Academic Press, London. 119, 2017.

34. GUNSCH C.K., CHENG Q., KINNEY K.A., SZANISZLO P.J., WHITMAN C.P. Identification of a homogentisate1,2-dioxygenase gene in the fungus Exophiala lecaniicorni: Analysis and implications. Appl. Microbiol. Biotechnol. 68 (3), 405, 2005.

35. WANG H.L., NIE L., LIJ., WANG Y.F., WANG G., WANG J.H., HAO Z.P. Characterization and assessment of volatile organic compounds (VOCs) emissions from typical industries. Chinese Sci. Bul. 58 (7), 724, 2013.

36. AWAD M.F., KRAUME M. Fungal diversity in activated sludge from membrane bioreactors in Berlin. Can. J. Microbiol. 57 (8), 693, 2011.

37. REHMAN A., SOHAIL ANJUM M., HASNAIN S. Cadmium biosorption by yeast, Candida tropicalis CBL-1, isolated from industrial wastewater. J. Gen. Appl. Microbiol. 56 (5), 359, 2010.

38. ELMALEH S., DEFRANCE M., GHOMMIDH C. Organic acids oxidation by Candida utilis: application to industrial waste water treatment. Process Biochem. 35 (5), 441, 1999.

39. OH S.Y., FONG J.J., PARK M.S., CHANG L., LIM Y.W. Identifying airborne fungi in Seoul, Korea using metagenomics. J. Microbiol. 52 (6), 465, 2014. 
40. BAHRAM M., VANDERPOOL D., PENT M., HILTUNEN M., RYBERG M. The genome and microbiome of a dikaryotic fungus (Inocybe terrigena, Inocybaceae) revealed by metagenomics. Environ. Microbiol. Rep. 2018.

41. BUÉE A.M., REICH M., MURAT C., MORIN E., NILSSON R.H., UROZ S., MUR C. 454 Pyrosequencing analyses of forest soils reveal an high fungal diversity unexpectedly. New Phytol. 184 (2), 449, 2014.

42. VIEGAS C., FARIA T., GOMES A.Q., SABINO R., SECO A., VIEGAS S. Fungal Contamination in Two Portuguese Wastewater Treatment Plants. J. Toxicol. Environ. Heal. Part A 77 (1-3), 90, 2014.

43. ABD EL-ZAHER E.H.F., ABOU-ZEID A.M., MOSTAFA A.A., ARIF D.M. Industrial oil wastewater treatment by free and immobilized Aspergillus niger KX759617 and the possibility of using it in crop irrigation. Rend Lincei. $\mathbf{2 8}$ (1), 93, 2017.

44. NHI-CONG L.T., MAI C.T.N., MINH N.N., HA H.P., LIEN D.T., TUAN D. VAN UYEN D.T.T. Degradation of sec -hexylbenzene and its metabolites by a biofilm- forming yeast Trichosporon asahii B1 isolated from oil-contaminated sediments in Quangninh coastal zone, Vietnam. J. Environ. Sci. Heal - Part A Toxic/Hazardous Subst. Environ. Eng. 51 (3), 267, 2016.

45. LAKSHMI V., NILANJANA D. Biodegradation of Caffeine by Trichosporon asahii Isolated from Caffeine Contaminated Soil. Int. J. Eng. Sci. Technol. 3 (11), 7988, 2011.

46. SUGIMORI D. Edible oil degradation by using yeast coculture of Rhodotorula pacifica ST3411 and Cryptococcus laurentii ST3412. Appl. Microbiol. Biotechnol. 82 (2), 351, 2009.

47. ELLEGAARD-JENSEN L., AAMAND J., KRAGELUND B.B., JOHNSEN A.H., ROSENDAHL S. Strains of the soil fungus Mortierella show different degradation potentials for the phenylurea herbicide diuron. Biodegradation. 24 (6), 765, 2013.

48. NARENDRULA-KOTHA R., NKONGOLO K.K. Bacterial and fungal resilience to long-term metal exposure in a mining region revealed by metagenomics sequencing. Ecol. Genet. Genomics. 2, 13, 2016. 